\title{
Urban Parish nurses: A qualitative analysis of the organization of work in community-based practices
}

\author{
Staci A. Young * \\ Department of Family and Community Medicine, Medical College of Wisconsin, Milwaukee, WI, United States
}

Received: May 22, 2015

Accepted: October 13, $2015 \quad$ Online Published: October 25, 2015

DOI: $10.5430 /$ jnep.v6n2p19

URL: http://dx.doi.org/10.5430/jnep.v6n2p19

\begin{abstract}
In the changing political economy of the health care environment, it is critical to understand the role of community providers serving vulnerable groups as central to their core service missions. Religion becomes salient in the work of health care providers in church communities. This study deconstructs and critically examines the factors that shape the work of nurses in urban congregations. The design utilized in-depth semi-structured interviews and a survey that included educational background, years in practice, congregation demographics and outreach activities. Nurses discussed how their faith-based work aligns along broader common dimensions of their practice. The organization of work is a useful sociological framework in which to explore this community-based nursing specialty.
\end{abstract}

Key Words: Qualitative research, Faith community nursing, Community-based nursing, Healthcare delivery, Work

\section{INTRODUCTION}

Addressing the myriad of health needs is critical to a patient centered model of care. This model recognizes that there is more to care than physical; needs can include emotional and spiritual roots. Community-based health professionals encounter patients in both clinical and non-clinical settings. In the changing political economy of the health care environment, it is critical to understand the role of community providers serving vulnerable groups as central to their core service missions. Successfully fulfilling their professional roles has direct implications for population health and ongoing funding of health services. Parish nurses are in a unique position to observe and comment upon relationships with community members as clients, congregational leadership, and health care delivery systems that support their work.

\subsection{Spirituality and public health practice}

Spirituality is a critical component to health care. Puchalski $^{[1]}$ stated that "spirituality speaks to what gives ultimate meaning and purpose to a person's life.” Broadly defined, this includes those individuals that are religious and nonreligious, as all at some point seek meaning and/or healing in life.

There is growing literature on the connection between religion and health, specifically health outcomes. There is a positive link between religious attendance, devotion and psychological well-being. ${ }^{[2,3]}$ The benefits to health outcomes are also tied to social integration and social support. In a faith community, this includes personal assistance and comfort that emerge from feelings of love, care and integration. Membership in faith communities is tied to improved selfesteem, personal efficacy, coping resources and behaviors, positive emotions and healthy beliefs. ${ }^{[4]}$

According to Vaux,${ }^{[5]}$ the front line of preventive and interventive health in our society is the church, the clergy, and the religious community. Historically, spirituality was integral to the practice of health organizations and institutions. ${ }^{[1,6]}$

\footnotetext{
*Correspondence: Staci A. Young; Email: syoung@mcw.edu; Address: Department of Family and Community Medicine, Medical College of Wisconsin, 8701 Watertown Plank Road, Milwaukee, WI, United States.
} 
Medical care was primary palliative, as there were limited options for curative services. Healers utilized a holistic approach encompassing physical, emotional, spiritual, and social care. Early U.S. hospitals were founded by religious orders whose primary mission was in service to the whole person. ${ }^{[1]}$ Providers selected health care out of a calling to serve and care for others.

With the rise of technology in the twentieth century, there was a shift to focusing on "cure" in the western world. This was embedded in the biomedical model and discussions of spirituality and religion diminished in the practice of medicine. ${ }^{[1]}$ Later in the twentieth century there was an increased interest and research in the linkages between spirituality and health outcomes with the rise in religious healing practices. Modern day nursing began to re-explore its spiritual roots. ${ }^{[7]}$ Many religious communities developed and implemented programs to link congregants to health resources. In the Christian community this included health ministry programs encompassing social support, health and spirituality. The most common health ministry program is parish nursing, also called faith community nursing.

\subsection{Parish nursing}

Churches have a long history of health care delivery for over 2,000 years. ${ }^{\left[{ }^{8,9]}\right.}$ The history of nursing itself is heavily linked to religious orders and congregations tending to the sick and poor. ${ }^{[8]}$ Historians cite the early Holy Wars prior to Greek and Roman times as a period during which religious women served as midwives, nurses and healers. Nursing gained the "status associated with religious faith from parishoners and the faith-based community members they served." ${ }^{\text {[10] }}$ Nursing has been associated with ministry to the whole person "in contrast to science which undergirds modern medicine."[7] As such, nursing is seen as a Christian calling. In 1998 the American Nurses Association (ANA) recognized "faith community nursing" as a specialty area, including standards of practice. ${ }^{[11]}$ It defines the specialty as:

“... the specialized practice of professional nursing that focuses on the intentional care of the spirit as part of the process of promoting wholistic health and preventing or minimizing illness in a faith community."

It is also consistent with the American Holistic Nurses Association, which states that the holistic nursing practice "recognizes the totality of the human being - the interconnectedness of body, mind, emotion, spirit, social/cultural, relationship, context, and environment." ${ }^{[12]}$ The ANA identified seven role functions for a faith community nurse: health educator, integrator of faith and health, personal health counselor, referral agent, trainer of volunteers, developer of support groups, and health advocate. The American Nurses Credentialing Center and the Health Ministries Association recently announced a new certification for faith community nursing which "serves to validate faith community nurses' unique knowledge, skills and contributions to patient care." ${ }^{\text {"13] }}$ It differs from traditional nursing in that it intentionally incorporates spiritual and religious practices as basic tenants of practice. Studies of parish nursing have focused on roles, professional development and the specific interventions they lead. This study provides a sociological framework to further deconstruct the work of these community based health professionals as a function of their religion and physical location, not merely their specialty.

The System of Professions Theory developed by Abbott ${ }^{[14]}$ provided the theoretical framework for the study. This theory emerged as an alternative to traditional concepts of professionalization that focus on structure rather than work. It is the changing nature of work that creates a focus on groups with common tasks. For example, professionals of varying levels of education and training may co-exist in the same setting, work with the same clients and thus share professional tasks. These tasks are "created, abolished, or reshaped by external forces, with consequent jostling and readjustment within the system of professions." ${ }^{[14]}$ Abbott posits that: 1) the essence of a profession is its work, not its organization; 2) there are many factors that control the content of that work; and 3) professions exist in an interrelated system. The objective of the study was to deconstruct and critically examine the factors that shape the work of Christian nurses in urban congregations. Specifically, the research questions of interest were:

(1) How do parish nurses define and organize their professional care work?

(2) What strategies are used by parish nurses to negotiate multiple roles and relationships while providing holistic care to their clients?

\section{Methods}

All study activities were pre-approved by the Medical College of Wisconsin's Institutional Review Board.

\subsection{Study design}

The study used a contextual interview approach to explore the culture (i.e., beliefs, behaviors) of parish nurses as a group. Contextual interviews allow the researcher to gather information and inquire about specific processes of the participant. The study also included a brief demographic survey to capture professional background and work setting. The data for this project was gathered from nurses in Milwau- 
kee, Wisconsin. Qualitative inquiry typically focuses on a small number of cases, selected purposefully. ${ }^{[15]}$ Conducting in-depth personal interviews using an open-ended, semi-structured interview guide is an effective, methodologically appropriate approach to enhance understanding of their health care work in these settings. Qualitative methodology is a flexible and powerful tool that can facilitate new areas for research. ${ }^{[16]}$ Increasingly these methods are advocated for in health-based research. ${ }^{[17]}$ Qualitative methodology aids in eliciting meaning and explores the impact for those experiencing the phenomenon. ${ }^{[18]}$

\subsection{Recruitment}

Snowball (chain) sampling was used as an approach for locating information rich cases. It is especially useful for this population as parish nurses are most likely to know of their peers that can be interviewed as critical cases. Participants were recruited through the Church of God in Christ state regional jurisdiction, the regional Catholic Archdiocese, hospital systems with parish nursing programs, and a local collaborative of cross-denominational churches. The diversity of settings and denominations captured the breadth of nursing activities, educational backgrounds, professional relationships, and the integration of services among settings. Participants were recruited via email and phone calls and were required to be 18 years of age or older. Those that agreed to participate were given an interview date and time based on their availability. The author's professional role was disclosed to participants at the time of recruitment and again at the beginning of the interview.

\subsection{Data collection}

Participants completed a 14-item survey that included educational background, years in practice, congregation demographics and outreach activities. Participants were then assigned a unique identification number. Survey data was entered into the Research Electronic Data Capture (REDCap), a secure, web-based application designed to support data capture for research studies. ${ }^{[19]}$

Interviews were conducted at the church where each nurse was employed, at local libraries with a private space, or the participant's home. There were no other observers present in the room during the interview. All participants signed an informed consent document before completing the survey and the interview. There was only one interview for each participant.

\subsection{Data analysis}

Descriptive statistics were used for survey data. Interviews were audio recorded and professionally transcribed. Hand written notes were taken for three interviews in which participants elected to not be audio recorded. Data was analyzed using MAXQDA, ${ }^{[20]}$ a password protected software program. Name identifying information was removed from the transcripts and linked back to the participant's identification number. Transcripts were coded using qualitative content analysis, by identifying, coding and categorizing patterns in the data. ${ }^{[15]}$ This began with reviewing field notes taken during reviewing transcripts and drafting preliminary codes. These codes were noted in the margins of the transcripts. The data was read several times to ensure completeness of assigned codes. Categorical themes emerged from code groups. Analysis continued until no new themes were identified.

\section{RESULTS}

There were a total of 32 nurses identified and recruited for participation. Of those contacted, 23 nurses from 22 congregations agreed to individual interviews (72\% response rate). Of the 23 nurses interviewed, 21 chose to complete a survey of demographic information. Interviews lasted from 45 minutes to 2 hours. All of the nurses were women, with $94 \%$ over the age of 40 . There was diversity in professional nursing background, including psychiatry, rehabilitation, oncology, and pediatrics. The years of parish nursing experience ranged from 4 to 36 years (mean $=12$ ). Table 1 outlines a demographic breakdown of nurse background, education and practice setting.

\subsection{Dimensions of parish nursing practice}

Existing tasks that nurse participants coordinated include health screenings, education, referring to community resources, and coordinating health fairs. These tasks were common across participants. Nurses discussed how their work aligns along broader common dimensions of their practice. The emergent themes of ministry, relationships, advocacy and visibility are outlined below.

\subsubsection{Ministry}

Nurses discussed their roles as not merely a collection of tasks to be accomplished, but as a greater purpose that aligns with spirituality and health. The theme "ministry" was selected to represent the ways in which the nurses spoke about their purpose and calling to practice in a faith community setting. One way this is operationalized is by praying with clients and sharing a spiritual connection. Several participants noted this as integral to what they do:

Now, when it come to the spirituality piece at the clinic, I'll do the same thing there. I'll stop and pray. I'll bring up - I don't hesitate to ask “do you have a belief or a faith?" Do you believe, you know? I don't have a problem anymore with 
praying with them, questioning them about their entity, as to their faith, and do they go to church, and how that can make a difference cause God does want you to be healthy. - nurse of 15 years (Church of God in Christ)

Any time a team member goes out to visit someone, it is our protocol that we do not leave without praying and sharing the word of God, so we offer it. If a patient receives it, it's up to them. We don't take it lightly. - nurse of 12 years (Pentecostal)

Table 1. Nurse demographic characteristics

\begin{tabular}{ll}
\hline Category & Total sample (n= 21) \\
& $\mathbf{n}(\%)$ \\
\hline Gender & $21(100)$ \\
Female & \\
Age & $0(0)$ \\
39 and under & $8(38)$ \\
$40-54$ & $13(62)$ \\
$55+$ & \\
Race & $16(76)$ \\
African-American & $5(24)$ \\
Caucasian & \\
Highest Degree Completed & $2(11)$ \\
Diploma & $2(11)$ \\
Associate's Degree & $8(44)$ \\
BSN & $6(33)$ \\
MSN & $3(14)$ \\
Did not report & \\
Years in Professional Nursing & $6(29)$ \\
10-19 years & $4(19)$ \\
20-29 years & $11(52)$ \\
30+ years & $12(10)$ \\
Employment Status as Parish Nurse & \\
Volunteer & $13(62)$ \\
Full-time & $5(24)$ \\
Part-time & $3(14)$ \\
Denomination & \\
Assembly of God & $2(10)$ \\
Baptist & $5(24)$ \\
Catholic & $3(14)$ \\
Church of God in Christ & $6(29)$ \\
Lutheran & $4(19)$ \\
Non-denominational & $1(4)$ \\
Congregation Size & \\
200-599 & \\
\hline 100-199 & \\
\hline
\end{tabular}

Additionally, parish nurses addressed balancing one's spiritual beliefs with western medicine. This is done by com- municating with clients about how they can benefit from medical treatment and still honor their spiritual beliefs. This is evidenced by the following comment:

You encourage the person to, of course, have their belief and of course, to believe that God is going to do their healing, but you also encourage the person to know that their doctor was given the skills, not just because of who he is. God gave the skills to this person to help you. God likes for us to help ourselves. - nurse of 20 years (Church of God in Christ)

Nurses realized that ministry includes appreciating the circumstances faced by their clients; this level of empathy is critical to reaching them.

I said all that to say that if you empathize - you can't tell people God is a healer if you ain't never been sick and He hasn't never healed you for anything or you haven't went through it with anybody. You really can't. You really shouldn't. That's my pattern of reaching people. - nurse of 7 years (Assembly of God)

\subsubsection{Relationships}

Ministering to clients is an integral step to building and sustaining relationships. Relationships occur at several levels: with clients, with clergy, and other health professionals and health systems. With clients, nurses are seen as immediately accessible for needs and questions:

I've had that parishioner call me, maybe at 2:00 or 3:00 in the morning and tell me they're having problems and they couldn't get hold of their doctor. So, my number was next. - nurse of 20 years (Church of God in Christ)

The relationships with the health care system consist of communications between parish nurses and their peers/colleagues based in hospitals and clinics.

Now, once she got discharged, the pastor and I went to visit her, went to her psychiatrist's meeting. And the psychiatrist was like, "I'm glad you guys are here because I've heard about your church and I, I didn't think you guys would tell her to stop taking her meds. But I want, I'm glad you're here..." Now, the beauty of that is, if I was not a parish nurse they wouldn't have talked to me. They wouldn't have dealt with me. Because of confidentiality. So a lot of doors are open to parish nurses. - nurse of 16 years (Church of God in Christ) 


\subsubsection{Advocacy}

In health care, advocacy is considered those activities that focus on patient needs and those of the public as a means of protecting the patient from harm. Nurses discussed the ways in which they advocated for their clients. This occurred in two primary ways: navigating the health care system and ensuring there were coordinated services to meet their needs.

So, I went with her to that appointment, but I knew about that appointment two months ago because her niece, who's a diabetic and takes care of her sister, my godmother's mother, she has those two. She said, "I have all these appointments and I'm not going to be able to take Auntie this time. Will you be able to?" I'm like, "Sure. I can handle that." So, it depends how much of a notice I get. - nurse of 7 years (Assembly of God)

Another nurse spoke of how she went to a client's home to assist her until home care could be arranged.

And I just so happened to went in there, she can get herself in and out of bed, she could get herself on and off the toilet, but she couldn't fix herself no food and she couldn't bathe herself. So she had flakes on her, she was so moist from not being washed, and dishes were, I don't know, just so happened I had somebody else with me... we got her all together and we took care of her until homecare got in there. - nurse of 20 years (Church of God in Christ)

\subsubsection{Visibility}

Nurses discussed the ways in which they are recognized in their faith community setting. This includes both physical visibility and awareness of congregation members as to their existence in the church. Historically, particularly in the Black church, the nurse had a much different role and they were recognizable by a specific uniform. This was discussed by participants as evidenced by the following comments:

That's what they called it, the Nurses Guild. All they really cared about was you showed up for the funerals. You passed out the tissues. I'm like, 'But what about an educational session on grieving?' - nurse of 7 years (Assembly of God)

So we were up at 4:30, looking for our white uniforms because, you know, that's what you wore to your nurses meeting, your white uniform and your cap. - nurse of 19 years (Missionary Baptist Church)
... we have the church nurse who sits out with the white uniforms and things like that and they help. And they'll cover up the ladies with the sheets if they faint or fall out in the Spirit or if they're praising the Lord and things get - they're there to help them pull themselves back together or whatever. - nurse of 5 years (Church of God in Christ)

This second comment notes not only the dress of parish nurses but their traditional roles. However, not all participants stated that they followed a specific dress code. The following woman explains her rationale for not doing so:

I will not - I don't put on the white uniform and sit down front. And not that anything is wrong with it. I just don't feel that's where my focus is because when I'm that far down front, I can't really see what's going in the [assembly]. - nurse of 5 years (Church of God in Christ)

I'm like, no, no. That's not what I want to do. I want someone to come to me if they're having some medical needs or anything like that, so we can advocate. - nurse of 19 years (Missionary Baptist Church)

\section{Discussion}

Returning to Abbott's System of Professions theory, we can re-examine the views of participants as not only a reflection of their professional practice (i.e., nursing), but as a set of tasks that are influenced by religion (i.e., Christianity) and location of their work. Their basic interventions of health screenings, education and sharing resources are consistent with other work that describes the roles of parish nurses. ${ }^{[21,22]}$ These tasks require training and experience that would be utilized in most other clinical settings. It is the broader dimensions of their practice (ministry, relationships, advocacy, and visibility) that should be further examined, as the location of their work is different from traditional health delivery settings. This is consistent with the second postulate of the theory, that many variables control the content of work. The American Nursing Association's recognition of faith community nursing and formalized standards of practice is arguably a move towards ownership of tasks (i.e., noting what work is done by nurses) and claiming jurisdiction by linking this work back to their profession.

\subsection{Ministry}

The nursing profession has its roots in the Christian concept of ministry. ${ }^{[7]}$ Meanings of ministry include serving, aiding in comfort, and being a spiritual guide. A ministry of caring includes a calling for neighbors to serve each other 
and attend to their physical and/or spiritual needs. As such, examining nursing as a ministry is a rich opportunity. Caring is an integral part of ministry in religious communities. It is essential to healing at the spiritual, physical, and emotional levels. Clergy and pastoral care workers share key tasks with nurses. These include providing concern and comfort; finding meaning in suffering; providing hope; and facilitating the expression of feelings. These tasks are common particularly with parish nurses. This is the essence of Abbott's theory, that through this examination we can understand the organization of work.

\subsection{Relationships}

Practicing in a faith community can affect the relationships that a parish nurse must form, including interactions with clients/congregation members, clergy, and other health professionals. Nurses that are employed by large health care systems must manage relationships - and expectations - of their employers, those of congregational leadership, and their clients. The relationships of nurses in traditional health care settings are rather structured and follow organizational guidelines. For example, a hospital-based nurse works with other floor nurses, physicians, administrators, students and residents in training, patients and families, among others. In a community setting, the professionals and community members with whom a nurse forms relationships are more dynamic and varied. In a church, the clergy is typically the head of the organization, and often has no clinical background or training. A nurse may also engage with pastoral care workers or others on a health ministry team with clinical training but this is not guaranteed. As such, the parish nurse may be training others in specific areas like health education.

A key component in forming and sustaining relationships with clergy and congregation members is building trust. This requires keeping confidential information and respecting boundaries. While the Health Insurance Portability and Accountability Act (HIPAA) requires health professionals to keep protected health information private, nurses in community settings are entrusted with all levels of client information such as marital problems, intimate relationships, and mental health issues. For example, one nurse in this study noted that a client had a serious health condition and did not want her to notify her children, and another nurse had to diffuse a potential encounter between a client's son and the police. Being in a community setting placed the nurses in a more intimate place with their clients and not only privy to extensive personal situations, but having to directly respond. In a hospital or clinic a nurse may have the option to refer a patient to a social worker. To defer responsibility or response in a community setting risks damaging existing relationships with clients. It is for this reason that parish nurses in this study supported the assertion that nurse graduates should first practice in a hospital setting before entering in a community setting such as a church. Indeed, the vast majority of participants were age 40 and older, and 53\% had been in nursing over 30 years. This is consistent with parish nursing data in a study by McGinnis and Zoske. ${ }^{[21]}$ These are highly experienced individuals that know their field quite well and could manage complex relationships with minimal or no direct supervision. A new graduate nurse with little professional experience may be challenged to handle both medical concerns and other critical relationships and contextual issues faced by clients.

\subsection{Advocacy}

To advocate is to "publicly defend, maintain, recommend, stand up for, or raise one's voice on behalf of a proposal or tenet."[23] One that advocates speaks on behalf of another person as that individual perceives his or her interests. ${ }^{\text {[24] }}$ While advocacy is commonly used in a legalistic sense, it takes on various definitions within the health professions. Activities generally focus on health conditions, resources, and the needs of the patient and the public. ${ }^{[25]}$ Schwartz $^{[24]}$ states that it is a means to safeguarding good patient care.

There are several levels of advocacy that are incorporated in the roles of health professionals. At the micro level is advocacy for the individual client/patient. Activities are embedded in everyday practice and vary based on individual client needs. According to Gruen and colleagues ${ }^{[23]}$ there are specific activities for advocates, both within and outside practice settings. Advocacy at the organizational/service level includes actions that increase efficacy of services. Advocacy at this level is of moderate complexity and very proactive. Advocates can work to improve systems of care in an institution, improve health care access among minority patients and provide free health care. ${ }^{[23]}$

In this study, nurses utilized their relationships with clergy and peers/colleagues in order to advocate for clients. Their role is that of a liaison to church leadership and/or health care team members that can provide care beyond the scope of the parish nurse. Additionally, the parish nurse may be better positioned to communicate the client's needs. What emerged from participants is that advocacy extends beyond these relationships. Parish nurses interface with home care workers, family members, law enforcement, and others deemed with providing aid to clients. Parish nurses are then in a position to advocate for client needs while still managing other relationships. 


\subsection{Visibility}

The visibility of the nurse in a faith community is different than in a traditional health care setting. In a church the nurse may be dressed no differently than the congregants, whereas in a clinic or hospital $\mathrm{h} / \mathrm{she}$ would be dressed in a uniform and perhaps an identification badge. Church settings have defined leaders and in many cases nurses depend on these individuals to alert congregants about their presence and roles. Nurses in this study varied in how they were promoted to the congregation. This includes sitting in a designated area of the church, wearing a uniform, a church bulletin, or the clergy announcing their presence while at the pulpit.

Beyond just the physical visibility of parish nurses in a defined space, the work of researchers Joan Liaschenko and Patricia Rodney provide insight into studying the (in)visibility of nursing work and the implications for practice. They posit that much of nursing work is actually invisible and this has consequences for practitioners and clients. Bjorklund, ${ }^{[26]}$ in her discussion on nursing work and the writing of Liaschenko and Rodney states that "nurses' sight (i.e., their co-constructed understanding of what falls under their gaze; indeed, even the actuality of what falls under their gaze) is largely unseen, except by other nurses." Specifically, what Bjorklund labels as nurses" "systems work" is invisible and not seen as having a traditional place within biomedicine. This includes addressing the issues that typically fall outside the role of hospital providers to directly address: poverty, its secondary effects, and homelessness. I would argue this is particularly true for community-based nurses, as they directly face these issues with their clients. Many professions are recognized and legitimized based on their worksite. For example, the hospital is most familiar for nursing and medicine. Yet while churches and communities are historically considered as early worksites for nursing professionals, "only certain aspects of care are accounted for and funded, while significant aspects of nursing care are not."[26] This has implications for health care reform and the accurate documentation of health care work in community settings.

It is notable in this study that the dimensions of practice are common across all Christian denominations including Baptist, Lutheran, Pentecostal, and Roman Catholic. While participants discussed the role of Christianity in their work, the specific denomination was not cited as a driving factor. This is consistent with the role of Christianity in the early development of nursing and medicine, in that its primary function was that of ministering to those in greatest need. The nurses in this study centralized service, ministry, advocacy, and being in relationship to their clients as core to their both their professional work and their calling as Christian women.

There are implications for professional health care delivery in church settings. The majority of respondents were volunteer nurses. This is not uncommon for churches that typically have constrained budgets and many fiscal demands that may not allow funding for additional (non-clergy) staff. Prior funding models for parish nurses by local health care systems presumed that churches would eventually support a portion of the costs. In Milwaukee, this has yet to be fully realized and as such there are fewer parish nurses paid fully by health care systems. This study demonstrates the critical role played by these health professionals - driven largely by their faith and physical location. Churches seeking to employ nurses need to consider funding mechanisms or appeal to other sources to support the need.

A study limitation is that, due to a snowball sampling technique, there may be potential study participants that were not identified for recruitment. Yet given the network of parish nurses in Milwaukee there is a level of certainty that many practicing parish nurses were indeed in the recruitment pool. While the study data may have unknown generalizability to the universe of parish nurses, given the breadth and richness of the data collected there is a degree of generalizability in relation to the study's phenomenon of interest - the organization of work among community health professionals. The data can be tied to a theoretical framework that encompasses the experience of the study participants.

\section{Conclusion}

Abbott $^{[14]}$ argues that professions exist in an interrelated system. It is within workplaces that professional complexities are highlighted. 'Workplace assimilation' is a process of knowledge transfer in which paraprofessionals and nonprofessionals can learn a given professions" knowledge systems. The product of the individuals, rather than his/her credentialing becomes paramount. As one study participant stated "If you do the work [of a parish nurse], you do the work." This is critical to examine, as the location of work can directly influence who performs certain tasks. In the area of parish nursing, the Christian church as a work location broadens our understanding of nursing tasks, who completes them, and under what circumstances. The organization of work is a useful sociological framework in which to explore this community-based nursing specialty.

\section{ACKNOWLEDGeMENTS}

This work was supported by the Association for the Sociology of Religion. The sponsor did not contribute to study design, data collection, analysis or preparation and submission of the manuscript. I would like to acknowledge the 
parish nurses for sharing their perspectives in contribution to this study. Their efforts to improve community health are to be highly commended.

\section{CONFLiCTS OF InTEREST DisClOSURE}

The author declares that there is no conflict of interest.

\section{REFERENCES}

[1] Puchalski C, Ferrell B. Making Health Care Whole. West Conshohocken, PA: Templeton Press; 2010.

[2] Levin J, Markides K. Religious attendance and psychological wellbeing in middle-aged and older Mexican Americans. Sociological Analysis. 1988; 49(1): 66-72. http://dx.doi.org/10.2307/3 711104

[3] Ellison G. Religious involvement and subjective well being. Journal of Health and Social Behavior. 1991; 32: 80-99. http://dx. doi.o $\mathrm{rg} / 10.2307 / 2136801$

[4] Colon-Baco E. The strength of religious beliefs is important for subjective well-being. Undergraduate Economic Review. 2010; 6(1): Article 11.

[5] Vaux K. Topics at the interface of medicine and theology. In Marty, M.E. \& Vaux, K.L. (Eds.) Health/Medicine and the Faith Traditions (185-213). Philadelphia: Fortress Press; 1982.

[6] Joel L. Parish nursing: As old as faith communities. American Journal of Nursing. 1998; 98: 7. PMid:9629075 http://dx.doi .org $/ 10.2307 / 3471884$

[7] Widerquist J, Davidhizar R. The ministry of nursing. Journal of Advanced Nursing. 1994; 19: 647-652. PMid:8021384 http://dx.d oi.org/10.1111/j.1365-2648.1994.tb01134.x

[8] Stewart L. Parish nursing: Renewing a long tradition of caring. Gastroenterology Nursing. 2000; 23(3): 116-120. http://dx.doi.o $\mathrm{rg} / 10.1097 / 00001610-200005000-00005$

[9] Levin J, Hein J. Engaging the faith community for public health advocacy: An agenda for the surgeon general. Journal of Religion and Health. 2013; 52(2): 368-385. PMid:23519766 http: //dx.doi.org/10.1007/s10943-013-9699-9

[10] Anaebere A, DeLilly C. Faith community nursing: Supporting mental health during life transitions. Issues in Mental Health Nursing. 2012; 33(5): 337-339. PMid:22545641 http://dx.doi.org/10. 3109/01612840.2011.631164

[11] American Nurses Association. Scope and standards for parish nursing practice. Washington, DC: American Nurses Publishing. 1998.

[12] American Holistic Nurses Association. 2014. Available from: http: //www .ahna.org/About-Us/What-is-Holistic-Nursing

[13] American Nurses Credentialing Center. ANCC and HMA announce first board certification for faith community nursing. 2014. Available from: http://hmassoc.org/ancc-and-hma-announce-fir st-board-certification-for-faith-community-nursing /\#more-2311
[14] Abbott A. The System of Professions: An Essay on the Division of Expert Labor. Chicago: University of Chicago Press; 1988.

[15] Patton M. Qualitative Research and Evaluation Methods (3rd Ed.). Thousand Oaks, CA: Sage Publications; 2002.

[16] Britten N. Qualitative research: qualitative interviews in medical research. British Medical Journal. 1999; 311(6999): 251-253. http://dx.doi.org/10.1136/bmj.311.6999.251

[17] Chew-Graham CA, May CR, Perry MS. Qualitative research and the problem of judgment: lessons from interviewing fellow professionals. Family Practice. 2002; 19(3): 285-289. http://dx.doi.org/10. 1093/fampra/19.3.285

[18] Turato ER. Qualitative and quantitative methods in health: definitions, differences and research subjects. Rev Saúde Pública. 2005; 39(3): 1-8.

[19] Harris P, Taylor R, Thielke R, et al. Research electronic data capture (REDCap) - A metadata-driven methodology and workflow process for providing translational research informatics support. Journal of Biomedical Informatics. 2009; 42(2): 377-81. PMid:18929686 http://dx.doi.org/10.1016/j.jbi.2008.08.010

[20] MAXQDA (1989-2015). VERBI Software - Consult - Sozialforschung GmbH, Berlin, Germany.

[21] McGinnis S, Zoske F. The emerging role of faith community nurses in prevention and management of chronic disease. Policy Politics Nursing Practice. 2008; 9(3): 173-180. PMid:18711213 http://dx.doi.org/10.1177/1527154408322560

[22] Roberts D. Parish nursing: Providing spiritual, physical, and emotional care in a small community parish. Clinical Nursing Studies. 2014; 2(2): 118-122. http://dx.doi.org/10.5430/cns.v2n2p 118

[23] Gruen R, Pearson S, Brennan T. Physician-citizens: Public roles and professional obligations. Journal of the American Medical Association. 2004; 291(1): 94-98. PMid:14709581 http://dx.doi .org $/ 10.1001 /$ jama.291.1.94

[24] Schwartz L. Is there an advocate in the house? The role of health care professionals in patient advocacy. Journal of Medical Ethics. 2002; 28: 37-40. http://dx.doi.org/10.1136/jme.28.1.37

[25] Negarendeh R, Oskouie F, Ahmadi F, et al. Patient advocacy: Barriers and facilitators. BMC Nursing. 2006; 5(3).

[26] Bjorklund P. Invisibility, moral knowledge and nursing work in the writings of Joan Liaschenko and Patricia Rodney. Nursing Ethics. 2004; 11(2): 110-121. http://dx.doi.org/10.1191/0969733 004ne677oa 